\title{
Nanostructuring of Surface Layer of 1.3505 Steel By Wedge Cylindrical Tool
}

\section{Skorobogatov A.S. ${ }^{1}$, Kuznetcov V.P. ${ }^{1,2}$, and Belorusets A.M. ${ }^{1}$}

${ }^{1}$ Ural Federal University named after the first President of Russia B.N.Yeltsin, 19 Mira str., Ekaterinburg, 620002, Russia

${ }^{2}$ M.N. Mikheev Institute of Metal Physics of the Ural Branch of the Russian Academy of Sciences, 18 S. Kovalevskoy str., Ekaterinburg, 620108, Russia

\section{Abstract}

This paper discusses the issues of normal load during burnishing by a wedge cylindrical tool that influences the surface hardening of the 1.3505 steel according to the criteria of microhardness and thickness of nanostructured layer. It has been established that burnishing with a normal force of 200 and $250 \mathrm{~N}$ provides formation of a nanostructured layer with a 4,3...5,5 $\mu \mathrm{m}$ thickness and a maximum microhardness of $1120 . . .1170 \mathrm{HV}_{0,05}$.

Keywords: nanostructure, surface layer, hardening, burnishing, wedge cylindrical tool, bearing steel.
Skorobogatov A.S.

a.s.skorobogatov@urfu.ru

Received: 25 February 2019

Accepted: 9 April 2019

Published: 15 April 2019

Publishing services provided by

Knowledge E

(c) Skorobogatov A.S. et al. This article is distributed under the terms of the Creative Commons Attribution License, which permits unrestricted use and redistribution provided that the original author and source are credited.

Selection and Peer-review under the responsibility of The Ural school-seminar of metal scientists-young researchers Conference Committee.

\section{Intorduction}

There is a known perspective technology of forming the nanostructured surface layer of structural steels during sliding of spherical indentor [1-2]. However, the conducted study showed that when using the spherical indentor on the rear relatively to the direction of sliding, the formation of tensile stresses of high level takes place. These stresses negatively influence the quality of forming surface [2]. Similar effect occurs due to indentor's clearance.

It has been known that when using the wedge cylindrical indentor, this effect practically disappears [3-4]. Thus, it is particularly important to develop the technology of forming the nanostructured surface of bearing steels during sliding of wedge indentor.

Within the framework of this paper, it is suggested to conduct burnishing using the cylindrical indentor with the angle of $2^{\circ}$ to the surface of a workpiece (fig. 1). As a result of normal load with the force $F_{n}$, indentation takes place at a depth $h_{b}$. The formed contact patch has a parabolic form with the width of footing $l_{c}$. 


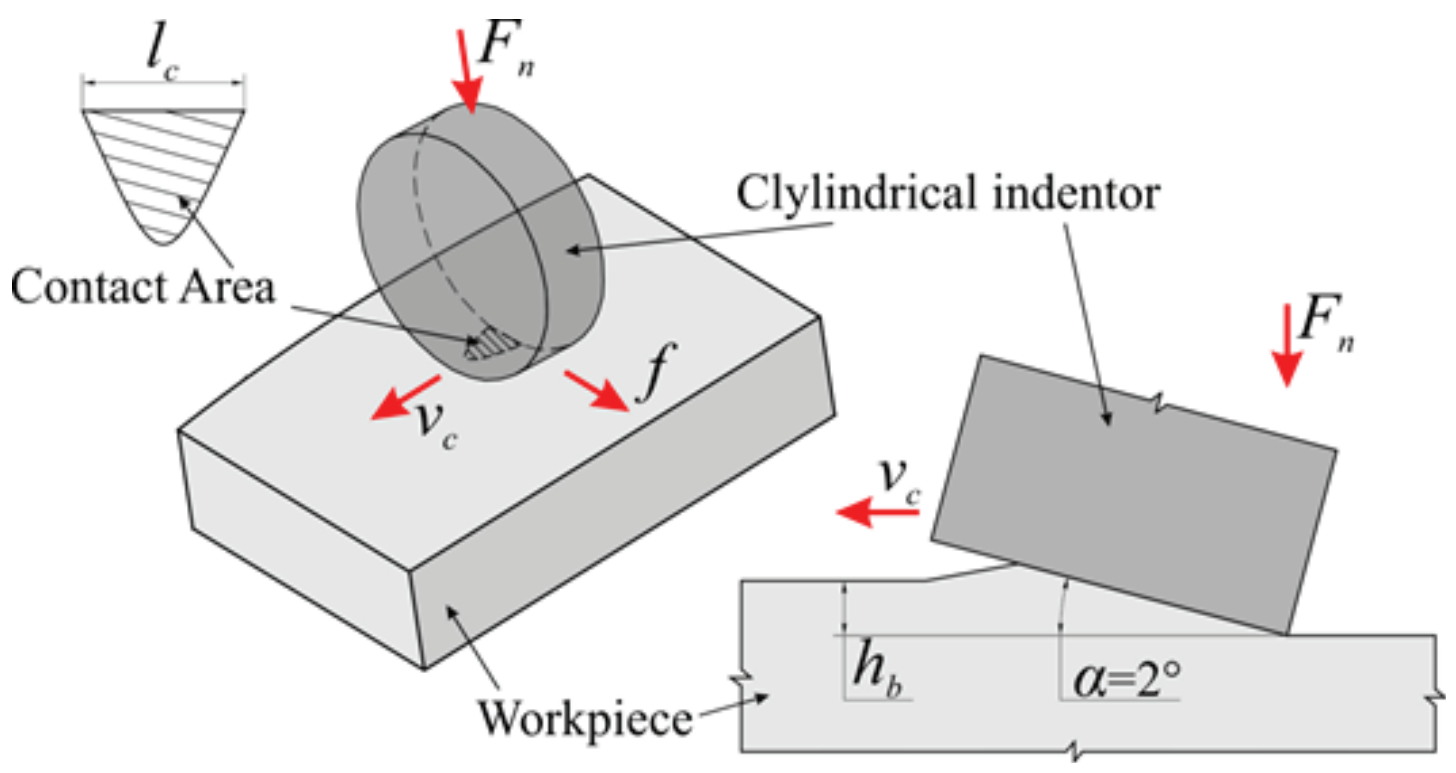

Figure 1: The scheme of burnishing a workpiece by wedge cylindrical tool.

In order to study the surface nanostructuring by wedge cylindrical indentor, a special tool was fabricated that uses a replaceable hard-metal insert SECO RNMN090300S02020 from boron nitride CBN500 as a working part.

The aim of the work is to define the influence of normal load on structure formation and microhardness of surface layer of bearing steel 1.3505 during burnishing by wedge cylindrical tool.

\section{Experimental Setup}

Experimental study was conducted on the samples of type "disc" of 1.3505 steel of 90 $\mathrm{mm}$ diameter and thickness of $12 \mathrm{~mm}$. Samples underwent heat treatment at $830^{\circ} \mathrm{C}$ and letting down at $300{ }^{\circ} \mathrm{C}$. After these operations their hardness was $56 \ldots 57 \mathrm{HRC}$. In order to provide surface flatness before burnishing, finish turning at a velocity of $80 \mathrm{~m} / \mathrm{min}$ and feed of 0,08 mm/rev were performed. The cutting depth was 0,2 mm. An arithmetic average of profile deviation of the surface after turning process was $\mathrm{Ra}=0,8 \mu \mathrm{m}$.

The burnishing of ring tracks with the width of $15 \mathrm{~mm}$ with different normal force for each: $100,150,200$, and $250 \mathrm{~N}$ was performed on the sample. The sliding velocity was established at a level of $25 \mathrm{~m} / \mathrm{min}$, the feed $-0,04 \mathrm{~mm} / \mathrm{rev}$. Burnishing was performed during the feeding of oil-cooling processing medium FUCHS into the processing zone.

In order to prepare cross-sections from processed tracks using electroerosion machine AgieCut Sprint 20, the samples of $20 \times 10 \mathrm{~mm}$ in size were cut. The surface under study was grinded and polished using the diamond suspension. 


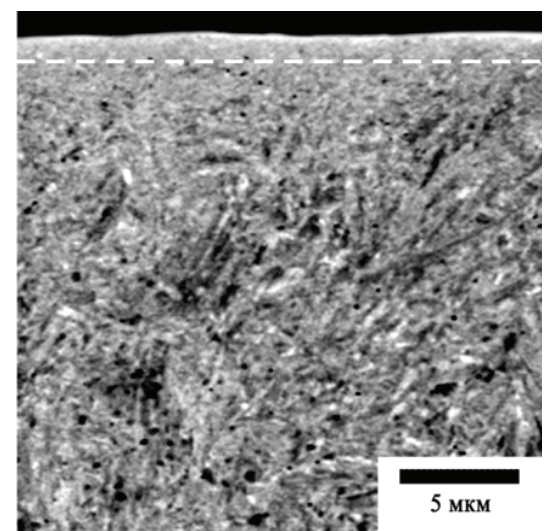

a) $F_{n}=100 \mathrm{~N}$

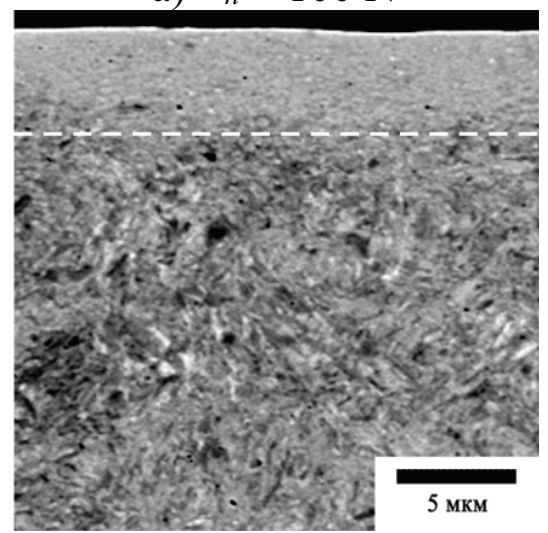

c) $F_{n}=200 \mathrm{~N}$

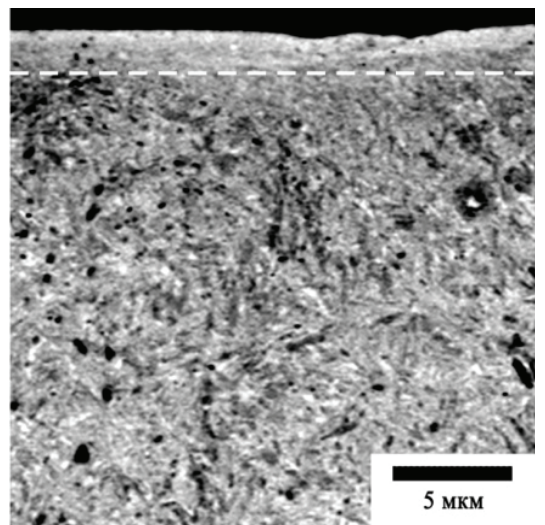

b) $F_{n}=150 \mathrm{~N}$

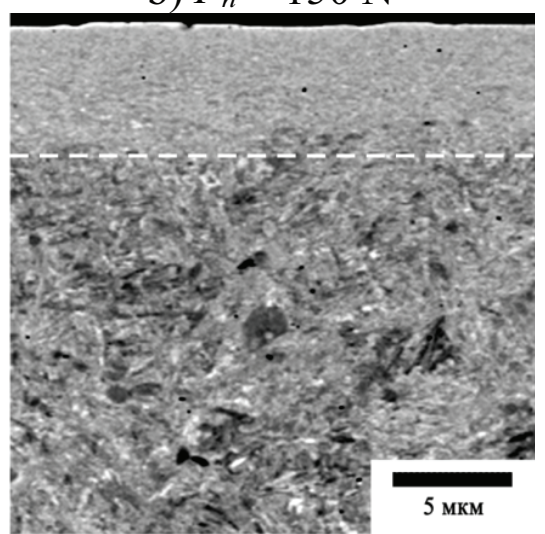

d) $F_{n}=250 \mathrm{~N}$

Figure 2: Microstructure of the surface layer after burnishing with different normal force.

\section{Results and Discussions}

The microstructure of the surface layer was studied using scanning-electron microscope Zeiss GrossBeam AURIGA. The analysis of received images (fig. 2) showed that when burnishing by wedge cylindrical tool, the formation of nanostructured surface is provided. With normal force of 100 and $150 \mathrm{~N}$ the thickness of nanostructured layer is 1,2...1,6 $\mu \mathrm{m}$. The increase of normal force to 200 and $250 \mathrm{~N}$ leads to the increase in thickness of the layer to 4,3 and $5,5 \mu \mathrm{m}$ accordingly.

Microdurometry in depth of the surface layer was conducted using the microhardness measuring tool Leica VMHT on the reconstructed indentation of Vicker pyramid with load of $0,05 \mathrm{kgf}$. Measurements were taken at a depth below the surface of $5 . .50 \mu \mathrm{m}$ with the interval of $5 \mu \mathrm{m}$, at a depth of $50 . .100 \mu \mathrm{m}$ with the interval of $10 \mu \mathrm{m}$ and the next one with the interval of $20 \mu \mathrm{m}$. The measurements were stopped when the microhardness of parent matrix of the material was reached. The values of microhardness were defined as an arithmetic average out of 5 successive indentions of the pyramid at equal distance from the surface. 
The achieved results show that the formation of the layer with microhardness of more than $1000 \mathrm{HV}_{0,05}$ requires the normal force of more than $150 \mathrm{~N}$. In case of burnishing with the force of $100 \mathrm{~N}$, the microhardness reaches the values close to $1000 \mathrm{HV}_{0,05}$ at distance of $10 \mu \mathrm{m}$ from the surface and do not exceed the mentioned level (Figure 3, a). During burnishing with the force of 150 and $200 \mathrm{~N}$ the maximum microhardness increases to $1125 \mathrm{HV}_{0,05}$, and the level of more than $1000 \mathrm{HV}_{0,05}$ is provided in the layer of 12 and 18 $\mu \mathrm{m}$ thickness accordingly (fig. $3, \mathrm{~b}$ and $\mathrm{c}$ ).

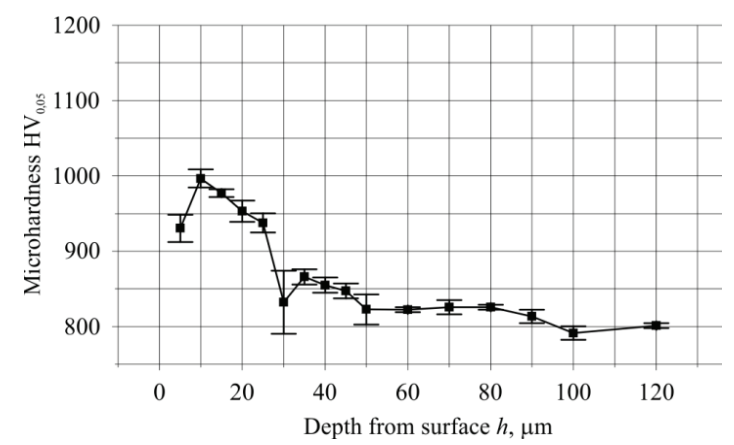

a) $F_{n}=100 \mathrm{~N}$

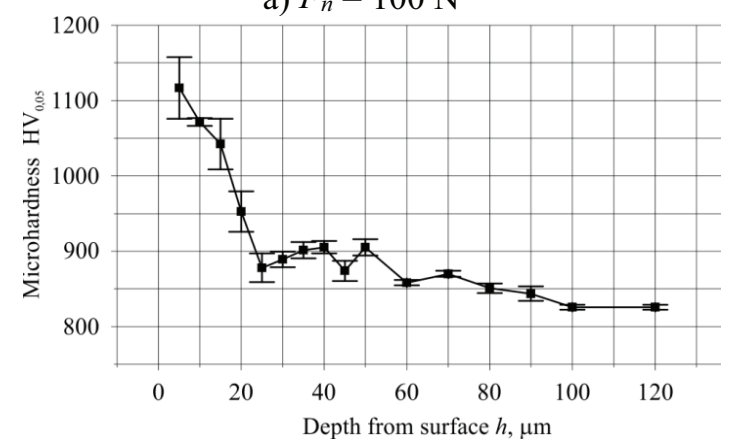

c) $F_{n}=200 \mathrm{~N}$

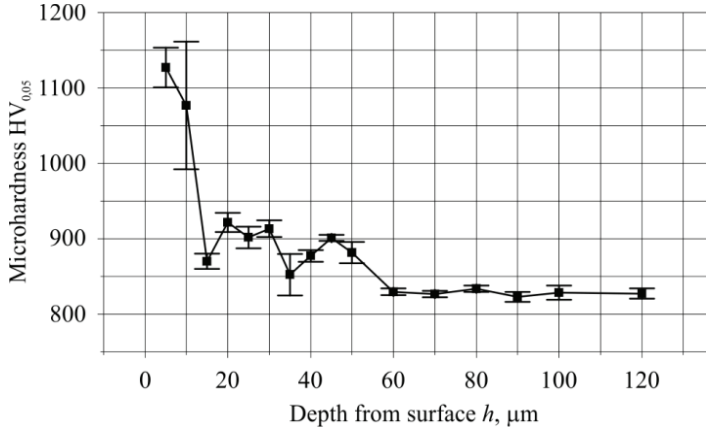

b) $F_{n}=150 \mathrm{~N}$

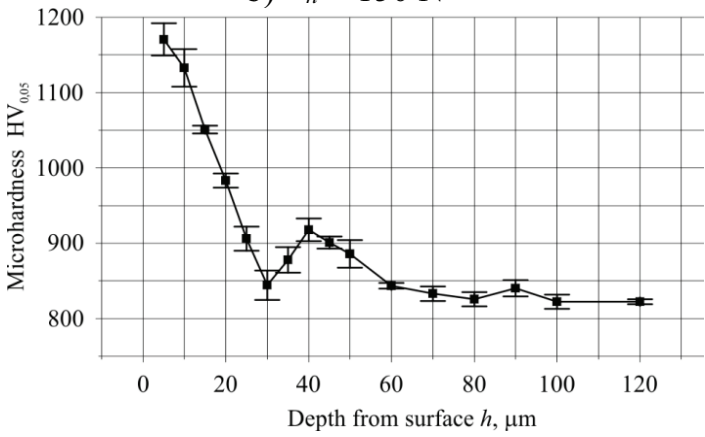

d) $F_{n}=250 \mathrm{~N}$

Figure 3: The distribution of microhardness in depth of the surface layer of samples after burnishing with differential normal force.

\section{Conclusions}

It may be concluded that burnishing by the wedge cylindrical tool is an effective method of nanostructuring of the surface layer of bearing steels. It has been also established that with the increase of normal force to $250 \mathrm{~N}$, the thickness of nanostructured layer to $20 \mu \mathrm{m}$ and the maximum microhardness of the surface to $1180 \mathrm{HV}_{0,05}$ also increases.

\section{References}

[1] Kuznetsov, V.P., Makarov, A.V., Psakhie, S.G., Savrai, R.A., Malygina, I.Y., Davydova, N.A., Tribological aspects in nanostructuring burnishing of structural steels. Phys 
Mesomech 17 (2014) 250-264. https://doi.org/10.1134/S102995991404002X

[2] Dmitriev, A.I., Kuznetsov, V.P., Nikonov, A.Y., Smolin, I.Y., Modeling of nanostructuring burnishing on different scales. Phys Mesomech 17 (2014) 243-249. https://doi.org/ 10.1134/S1029959914040018

[3] Sundaram, N.K., Guo, Y., Chandrasekar, S., Mesoscale Folding, Instability, and Disruption of Laminar Flow in Metal Surfaces. Phys. Rev. Lett. 109 (2012) 106001. https://doi.org/10.1103/PhysRevLett.109.106001

[4] Wang, X., Xicheng, W., Zhang, J., Li, R., Hua, M., Wang, W., Formation of Nanocrystallized Structure in Worn Surface Layer of T10 Steel against 20CrMnTi Steel during Dry Rubbing. Journal of Nanomaterials 2016 (2016) 1-6. https://doi.org/10.1155/2016/ 4631851 